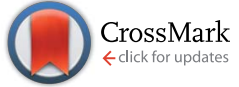

Cite this: RSC Adv., 2016, 6, 8
Received 9th November 2015 Accepted 13th December 2015

DOI: $10.1039 / c 5 r a 23624 j$

www.rsc.org/advances

\section{Qualitative and quantitative investigation of organophosphates in an electrochemically and thermally treated lithium hexafluorophosphate- based lithium ion battery electrolyte by a developed liquid chromatography-tandem quadrupole mass spectrometry method $\dagger$}

Vadim Kraft, Waldemar Weber, Benjamin Streipert, Ralf Wagner, Carola Schultz, Martin Winter and Sascha Nowak*

\begin{abstract}
The presented work was focused on the development of a new liquid chromatography-tandem quadrupole mass spectrometry method (LC-MS/MS) for the identification and quantification of organophosphates in lithium hexafluorophosphate $\left(\mathrm{LiPF}_{6}\right)$-based lithium ion battery electrolytes. The investigated electrolyte consists of $1 \mathrm{M} \mathrm{LiPF}_{6}$ dissolved in ethylene carbonate/ethyl methyl carbonate (50/50, wt\%) and was treated electrochemically and thermally. For the electrochemical experiments, the cut-off potential in the half cells was held at $5.5 \mathrm{~V}$ for $72 \mathrm{~h}$. The thermal degradation experiments were performed in aluminum vials at $95{ }^{\circ} \mathrm{C}$ for a period of 13 days. In the first part of this work, an already established gas chromatography-mass spectrometry (GC-MS) method for identification of dimethyl fluorophosphates (DMFP) and diethyl fluorophosphate (DEFP) was applied. In the second part, the LC-MS/MS method including determination of characteristic transitions in a product ion scan was developed. The developed method was applied for the identification of various analytes in the decomposed electrolytes. In addition, a possible formation of ionic and non-ionic OPs based on findings of this work and our previous reports is presented. In the third and final part, a quantification study of DMFP and DEFP was performed with a newly developed LC-MS/MS method and compared with results obtained by GC-MS. In addition, trimethyl phosphate (TMP) and triethyl phosphate (TEP) were quantified. These studies included the investigation of the suppression effects caused by the sample matrix during the application of the LC-MS/MS method.
\end{abstract}

\section{Introduction}

In recent years, the lithium ion battery (LIB) technology has an increasing importance for both domestic and industrial sectors. ${ }^{1,2}$ Usually, investigations are focused on the development of new materials for electrodes and electrolytes which should further improve the cycle stability and energy density of LIBs. ${ }^{3}$ A high energy density is summarized by a high voltage and a high capacity and it is crucial for the hybrid electric vehicle and the plug-in hybrid electric vehicle utilization. ${ }^{4}$ One of the approaches to improve energy density is the application of high voltage cathode materials such as $\mathrm{LiNi}_{0.5} \mathrm{Mn}_{1.5} \mathrm{O}_{4}$ (LNMO). Although, the theoretical capacity of LNMO is

University of Münster, MEET Battery Research Center, Institute of Physical Chemistry, Corrensstraße 46, 48149 Münster, Germany.E-mail: sascha.nowak@uni-muenster.de; Fax: +49-251-83-36032

$\dagger$ Electronic supplementary information (ESI) available. See DOI: 10.1039/c5ra23624j moderate $\left(147 \mathrm{~mA} \mathrm{~h} \mathrm{~g}^{-1}\right),{ }^{5}$ this cathode material can be operated at high voltages up to $4.7 \mathrm{~V}$ (ref. 5) making it promising for the electromobility industry. The most widely used electrolytes deployed in commercial LIBs are based on the electrolyte solution of $1 \mathrm{M} \mathrm{LiPF}_{6}$ dissolved in a mixture of organic carbonates. ${ }^{6}$ Their dominance on the marked is explained by excellent performance properties including ion conductivity, ${ }^{7}$ supporting solid electrolyte interphase formation (SEI) at the anode ${ }^{8}$ and protection of the aluminum current collector at the positive electrode. ${ }^{9}$ The main drawback of $\mathrm{LiPF}_{6}$ dissolved in organic carbonates is the chemical and thermal instability of the P-F bond. ${ }^{7} \mathrm{LiPF}_{6}$ undergoes the decomposition to high reactive $\mathrm{PF}_{5}$, which results in formation of inter alia $\mathrm{POF}_{3}, \mathrm{HF}$, alkyl fluorides and $\mathrm{CO}_{2} \cdot{ }^{10,11}$ Furthermore, the electrochemical instability of $\mathrm{LiPF}_{6} /$ organic carbonates based electrolytes is well known limiting their application at high voltages. ${ }^{12}$

An specific class of decomposition products generated during thermal decomposition of $\mathrm{LiPF}_{6}$-based electrolytes is 
represented by organophosphates (OPs), which are formed by reaction of $\mathrm{POF}_{3}$ with organic carbonates. ${ }^{10}$ Within the group of OPs, special attention to alkyl fluorophosphates should be paid. At least two of them, DMFP and DEFP, are very hazardous; their toxicity ${ }^{13}$ is comparable to diisopropyl fluorophosphate. ${ }^{14}$ These compounds are nerve agents, whose toxic effect bases on the irreversible reaction with a mammal enzyme acetylcholinesterase. ${ }^{15}$ Furthermore, these compounds were recently found in material from a lithium ion battery recycling process using GC-MS. ${ }^{16}$ With regard to the increasing demand on LIB working at high potentials, investigations regarding the quantification of any decomposition products should be performed.

The analysis of OPs and electrolyte degradation in LIB electrolytes was already performed with different analytical techniques including nuclear magnetic resonance spectroscopy (NMR), ${ }^{\mathbf{1 0 , 1 7}}$ GC-MS ${ }^{\mathbf{1 8 - 2 0}}$ including supercritical extraction steps, ${ }^{21,22}$ high resolution-electrospray ionization-mass spectrometry (HR-ESI-MS) ${ }^{23-25}$ and low temperature plasma-ambient ionization-high resolution-mass spectrometry (LTP-HR-MS). ${ }^{26}$ In particular, both ionic and non-ionic OPs were analyzed by GC-MS ${ }^{20,27}$ or ion chromatography hyphenated to tandem quadrupole mass spectrometry (IC-MS/MS), ${ }^{28}$ two dimensional ion chromatography-mass spectrometry (IC-IC-MS) ${ }^{29}$ and inductively coupled plasma-mass spectrometry-optical emission spectrometry (IC-ICP-OES). ${ }^{30}$ Almost all studies with these methods were focused on identification of the OPs. The quantitative analysis is complicated because of the absence of commercial standards. The concentration was determined by GC-MS and only for DMFP and DEFP with limits of detection (LOD) in the low ppm range for both compounds. ${ }^{16,20}$ The study of trialkyl phosphates, as further degradation products, was not performed due to their low contents. The LC-MS/MS technique working in a multiple reaction monitoring scan (MRM) mode is more specific as total ion current (TIC) or selective ion monitoring (SIM) modes of GC-MS. The schematic illustration of measurements obtained in the MRM mode with a triple quadrupole instrument is shown in Fig. S1. $\dagger$ After the separation on the chromatographic column and ionization in the ESI source, the molecular ion of a studied analyte is selected by the first quadrupole and transmitted to the second quadrupole used as a collision cell, which is filled with nitrogen as a collision gas. The collision results in formation of fragments, whose separation is performed by the third quadrupole. A fragment with highest intensity obtained by a defined value of a collision energy improves limits of detection. Compared to the MRM mode, both, TIC and SIM modes are applied with one quadrupole mass separator. The TIC mode measures the whole mass range, therefore the analytes are strongly interfered by matrix resulting in high limits of detection. In the SIM mode the molecule ions of the analytes are selected, which improves their detection. Nevertheless, measurements of the analytes and matrix compounds with the same mass results in the co-elution of the signals. The MRM mode is able to distinguish between the analyte and matrix compounds due to determination of specific fragments of the analyte, which increases in this mode, provided the characteristic fragmentation was determined. This technique was applied for the determination of trialkyl phosphates as flame retardants and plasticizers in drinking and surface waters $^{31-34}$ or air samples ${ }^{35}$ with low instrumental LODs. In the presented work, we developed a new LC-MS/MS method for study of non-ionic organophosphates, which was then applied for the identification and quantification of OPs electrochemically and thermally generated in a $\mathrm{LiPF}_{6} /$ organic carbonates LIB electrolyte. The electrolyte samples were treated at elevated cathode potential or high temperature in order to generate the desired analytes in high concentrations.

\section{Experimental part}

\subsection{Chemicals and materials}

The battery grade SelectiLyte ${ }^{\mathrm{TM}}$ LP50 electrolyte (BASF, Ludwigshafen, Germany) consists of $1 \mathrm{M} \mathrm{LP_{6 }}$ in ethylene carbonate/ethyl methyl carbonate (EC/EMC, 50/50 wt\%). Deionized water for the preparation of eluents, standard solutions and dilution of analytes was produced with a Milli-Q water system using a LC-PAK cartridge (Bedford, USA). Methanol, acetonitrile (MeOH, ACN, both HPLC gradient grade) and ethanol (EtOH, 99.8\%) were ordered from VWR (Bruchsal, Germany). DMFP and DEFP (both $>99.6 \%$ ) were synthesized according to literature. ${ }^{20} \mathrm{HCOOH}$ (98-100\% for analysis) was ordered from Merck (Darmstadt, Germany). Trimethyl phosphate (TMP > 99\%), triethyl phosphate (TEP, 99.8\%), 2-methoxyethanol (99.8\%) and the electrode material for LNMO were purchased from Sigma Aldrich (Steinheim, Germany). 2-Ethoxyethanol (99\%) was ordered from Alfa Aesar (Lancashire, Great Britain). Dimethyl ethyl phosphate (DMEP), diethyl methyl phosphate (DEMP), ethyl methyl fluorophosphate (EMFP) and alkoxyethyl dialkyl phosphates were synthesized according to literature. ${ }^{20}$ The nonwoven material (FS 2226) for the separators was purchased from Freudenberg Nonwovens (Weinheim, Germany). For thermal aging experiments, $10 \mathrm{ml}$ aluminum vials with butyl/polytetrafluoroethylene (PTFE) caps were used (Leicht\&Appel GmbH, Bad Gandersheim, Germany).

\subsection{LC-ESI-MS conditions}

The liquid chromatography studies were performed on an Ultimate 3000 HPLC system, which was controlled by a Chromeleon ${ }^{\mathrm{TM}}$ 7.2 Chromatography Data System software (Thermo Scientific, Waltham, USA). The separations were carried out on an Acclaim ${ }^{\mathrm{TM}} 120$ column (C18, $4.6 \times 250 \mathrm{~mm}$, Thermo Scientific) at $30{ }^{\circ} \mathrm{C}$ column oven temperature with $40 \%$

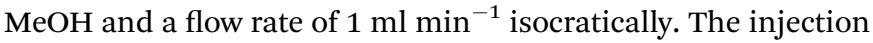
volume was $5 \mu \mathrm{l}$. The mass spectrometric measurements were performed using a triple quadrupole instrument $3200 \mathrm{LC} / \mathrm{MS} /$ MS (AB Sciex, Framingham, USA). The ESI-MS instrument was controlled with the Analyst 1.5.2 software (AB Sciex, Framingham, USA). The infusion of standard substances in a product ion scan mode was performed at a spray voltage of $4500 \mathrm{~V}$; the curtain gas was set to $15 \mathrm{psi}$; the nebulizer and dry gas were set to 25 psi and 0 psi, respectively; the temperature of the turbo gas was $0{ }^{\circ} \mathrm{C}$. The OPs were diluted $\left(1: 10^{5}, \mathrm{v} / \mathrm{v}\right)$ in water/ACN $(1: 1$, $\mathrm{v} / \mathrm{v}$ ) mixture containing $0.1 \mathrm{vol} \% \mathrm{HCOOH}$. The ion spray voltage in LC-MS and LC-MS/MS experiments was set to $5500 \mathrm{~V}$, the 
curtain gas was set to $25 \mathrm{psi}$, the nebulizer and dry gas were set to 45 psi and temperature of the turbo gas was $550{ }^{\circ} \mathrm{C}$. The declustering potential was set to $35 \mathrm{~V}$ for TMP and TEP or $30 \mathrm{~V}$ for other compounds, the entrance potential was $5 \mathrm{~V}$, the collision cell exit potential was $4 \mathrm{~V}$. The collision energy was set to $12 \mathrm{eV}$ for TMP and TEP or $15 \mathrm{eV}$ for other compounds. The scan time was $200 \mathrm{~ms}$. For TIC measurements with LC-MS, the electrolyte samples were diluted 1: 40 (v/v) in ACN. For quantification of DMFP and DEFP an external six-point calibration in a range of $2-100$ ppmv was performed $\left(R^{2}>0.998\right)$. The quantification of TMP and TEP was carried out with an external sixpoint calibration in a range of $0.01-0.5 \mathrm{ppmv}\left(R^{2}>0.999\right)$. The identification and the quantification of the organophosphates with LC-MS/MS in a MRM mode and limit of detection (LOD) studies were performed by the dilution factor of $1: 100(\mathrm{v} / \mathrm{v})$ in ACN. Each standard solution was measured five times; the samples were measured three times. Table $\mathrm{S} 1 \dagger$ lists the instrumental LOD values of DMFP, DEFP, TMP and TEP obtained with LC-MS/MS and calculated according to DIN 32645.

\subsection{GC-MS conditions}

The GC-MS measurements were performed on a GCMS-QP2010 Ultra GC-MS equipped with an AOC-5000 Plus autosampler and an OPTIC-4 injection system (Shimadzu, Duisburg, Germany). The analytes were separated on a Supelco SLB-5 ms column $(30 \mathrm{~m}, 0.25 \mathrm{~mm} \times 0.25 \mu \mathrm{m})$ from Sigma-Aldrich (Seelze, Germany). As carrier gas helium (6.0) with a column flow of 1

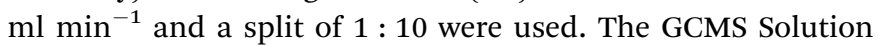
software (GCMS Real Time Analysis and GCMS Postrun Analysis) was used for instrument control and data analysis (Shimadzu, Duisburg, Germany). $1 \mu$ of the diluted samples (1: 100 vol\%, ACN) was injected at an injection temperature of $230{ }^{\circ} \mathrm{C}$. The measurements were performed with following column oven program: starting with $40{ }^{\circ} \mathrm{C}$ for $1 \mathrm{~min}$, the temperature was increased with a rate of $3{ }^{\circ} \mathrm{C} \min ^{-1}$ to $60{ }^{\circ} \mathrm{C}$, then with $30{ }^{\circ} \mathrm{C}$ $\mathrm{min}^{-1}$ to $210^{\circ} \mathrm{C}$ and held finally for $1 \mathrm{~min}$. Electron impact (EI) ionization was used at an ion source temperature of $200{ }^{\circ} \mathrm{C}$, a filament voltage of $70 \mathrm{~V}$ and a GC-MS interface temperature of $250{ }^{\circ} \mathrm{C}$. The quantification of DMFP and DEFP an external sixpoint calibration in a range of $2-100$ ppmv was carried out in a SIM mode $\left(R^{2}>0.996\right)$. Following mass fragments were used: $\mathrm{m} / \mathrm{z} 98$ for DMFP, $\mathrm{m} / \mathrm{z} 113$ for DEPF, $\mathrm{m} / \mathrm{z} 110$ for TMP and $\mathrm{m} / \mathrm{z} 155$ for TEP. The LOD values calculated according to DIN 32645 are presented in Table $\mathbf{S 1 . \dagger}$

\subsection{Electrochemical and thermal aging experiments}

The used LMNO electrodes were composed of $85 \mathrm{wt} \%$ LMNO, $7 \mathrm{wt} \%$ polyvinylidene difluoride (PVdF, Kynar® 761) and $8 \mathrm{wt} \%$ carbon black SuperC65 (Imerys). The preparation procedure is described by Kasnatscheew et al. ${ }^{36}$ The active mass loading of the electrodes was around $14 \mathrm{mg} \mathrm{cm}^{-1}$. The measurements were carried out in 2032 coin cells. As counter electrode, Li-metal was used. Polyolefin separators FS 2226 (6 fold) were soaked with $120 \mu$ lectrolyte. The potentiostatic experiments were carried out on a battery tester (Series 4000 from MACCOR) at $20{ }^{\circ} \mathrm{C}$. The LNMO/Li half cells were charged/delithiated to the upper cut-off potential of $5.5 \mathrm{~V} v s$. $\mathrm{Li} / \mathrm{Li}^{+}$. After reaching the desired cut-off potential, the potential was held for $72 \mathrm{~h}$. The cells were disassembled in the discharged state $\left(3.0 \mathrm{~V} v s . \mathrm{Li} / \mathrm{Li}^{+}\right)$in an argon filled glove box. After the electrochemical experiments, the separators were placed into plastic vials (Eppendorf Hamburg, Germany) and centrifuged at $8500 \mathrm{rpm}$ for $5 \mathrm{~min}$. The thermal decomposition of samples was achieved by heating $1 \mathrm{ml}$ of the electrolyte in $10 \mathrm{ml}$ aluminum vials with butyl/PTFE caps at $95{ }^{\circ} \mathrm{C}$ for 13 days.

\subsection{Evaluation of suppression effects caused by matrix}

The evaluation of suppression effects caused by the matrix was performed according to work of Chen et al. ${ }^{37} 50 \mu \mathrm{l}$ of the diluted solution (1:50, v/v in ACN for DMFP and DEFP and $1: 150, \mathrm{v} / \mathrm{v}$ in ACN for TMP and TEP) of the decomposed electrolytes were mixed with $50 \mu \mathrm{l}$ of $10 \mathrm{ppmv}$ DMFP/DEFP standard or $2 \mathrm{ppmv}$ TMP/TEP standard (sample $A_{i}$ ). Sample $B_{i}$ contained $50 \mu$ of the diluted sample $(1: 50, \mathrm{v} / \mathrm{v}$ in ACN for DMFP and DEFP and $1: 150, \mathrm{v} / \mathrm{v}$ in ACN for TMP and TEP), which was dissolved in $50 \mu \mathrm{l}$ of ACN. The third sample, $\mathrm{C}_{\mathrm{i}}$, was obtained by mixing of $50 \mu \mathrm{l}$ of $10 \mathrm{ppmv}$ DMFP/DEFP standard or $2 \mathrm{ppmv}$ TMP/TEP standard with $50 \mu \mathrm{l}$ of ACN. The matrix effects (ME, \%) were calculated as followed:

$$
\operatorname{ME}[\%]=100 \times\left(\mathrm{A}_{\mathrm{i}}-\mathrm{B}_{\mathrm{i}}\right) / \mathrm{C}_{\mathrm{i}}
$$

\section{Results and discussion}

\subsection{Determination of organophosphates by GC-MS}

Based on the work of Weber et al. ${ }^{20}$ dialkyl fluorophosphates were determined in thermally and electrochemically aged LP50 electrolytes. Fig. 1 displays the mass traces of analytes in the range of 3.8 and $8.4 \mathrm{~min}$, which were generated in an electrochemical aged sample. All three compounds, DMFP $(\mathrm{m} / z$ 98), DEFP $(m / z 113)$ and EMFP $(m / z$ 98), are clearly separated and could be detected with high intensity in both, the electrochemically and thermally degraded electrolytes. The identification of DMFP and DEFP is additionally supported by mass spectra and the retention time obtained with synthesized

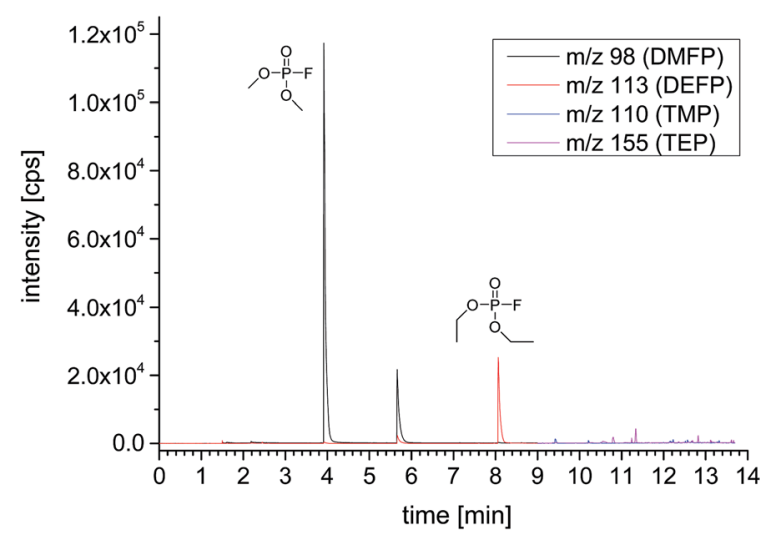

Fig. 1 SIM gas chromatograms of the investigated OPs generated in an electrochemically decomposed LP50 electrolyte. The peak at 5.9 min with $\mathrm{m} / \mathrm{z} 113$ can be assigned to the presence of EMFP. 
standards. Furthermore, the mass traces of TMP $(\mathrm{m} / z$ 110) and TEP $(m / z 155)$ as possible products of dialkyl fluorophosphates were monitored. Their commercially available standards have higher retention times compared to dialkyl fluorophosphates: TMP $\left(t_{\mathrm{R}}=9.4 \mathrm{~min}\right)$, TEP $\left(t_{\mathrm{R}}=11.2 \mathrm{~min}\right)$. The determination of the trialkyl phosphates in aged electrolytes is not reliable, since the occurrence of co-eluting signals of the studied $\mathrm{m} / \mathrm{z}$ values is accompanied by very low intensity for the retention times measured with standards. In addition, these compounds constitute only minor products of $\mathrm{LiPF}_{6}$ degradation, which further complicates their study by GC-MS. ${ }^{20}$

\subsection{ESI-MS/MS experiments}

Preliminary tests with TIC mode measurements of both thermally and electrochemically aged electrolytes reveal a very complex matrix. The mass chromatograms contain many signals, where assignment could not be achieved. The interpretation is additionally complicated by the presence of both $\mathrm{Na}^{+}$and $\mathrm{NH}_{4}^{+}$adducts. By searching for the molecule peaks $\left(\mathrm{M}+\mathrm{H}^{+}\right)$of OPs found by GC-MS (see 3.1) in a SIM mode, several co-eluted signals are detectable, which inhibits the identification. A MRM mode, as a characteristic LC-MS/MS mode, is more specific and sensitive compared to TIC or SIM, but it requires detailed knowledge about the fragmentation of the analytes. In Table 1, the chemical structures, monitored [ $\mathrm{M}$ $+\mathrm{H}]^{+}$, abbreviations and resulting fragments obtained by infusion of the standards of commercially available or synthesized OPs in a product ion scan mode are presented. The signal characteristic is strongly dependent from the presence of a proton donating compound. The addition of $20 \mathrm{mM}$ formic acid significantly increases the signal stability.

Furthermore, DMFP, DEFP and several alkoxyethyl dialkyl phosphates (see Table 1), which are commercially not available were synthesized to support the further identification process. The products are contaminated with different OPs, which were detected by LC-ESI-MS in the TIC mode. These OPs are the result of the trans-esterification process. Since the purity of the substances was not sufficient enough for quantitative measurements, they were only used for identification purposes.

In general, highly resolved fragmentation patterns are accessible for all analytes, which is demonstrated on an example of six OPs in Fig. 2. The fragments of other OPs are

Table 1 Chemical structures, monitored $\left[\mathrm{M}+\mathrm{H}^{+}\right.$, abbreviations and fragments obtained with the product ion scans of the investigated compounds

\begin{tabular}{|c|c|c|c|c|}
\hline Compound & Chemical structure & Monitored $[\mathrm{M}+\mathrm{H}]^{+}(\mathrm{m} / z)$ & Abbreviation & Fragments $(m / z)$ \\
\hline Dimethyl fluorophosphate & & 129 & DMFP & $113,109,97,95$ \\
\hline Diethyl fluorophosphate & & 157 & DEFP & 129,101 \\
\hline Trimethyl phosphate & & 141 & TMP & $127,109,95,79,47$ \\
\hline Triethyl phosphate & & 183 & TEP & $155,127,99$ \\
\hline Dimethyl ethyl phosphate & & 155 & DMEP & $127,109,99,95$ \\
\hline Diethyl methyl phosphate & & 169 & DEMP & $141,113,95$ \\
\hline Methoxyethyl dimethyl phosphate & & 185 & MEDMP & $141,127,109,59$ \\
\hline Ethoxyethyl dimethyl phosphate & & 199 & EEDMP & $127,73,45$ \\
\hline Methoxyethyl diethyl phosphate & & 213 & MEDEP & $185,155,127,99,59$ \\
\hline Ethoxyethyl diethyl phosphate & & 227 & EEDEP & $155,127,99,73,45$ \\
\hline
\end{tabular}


a)

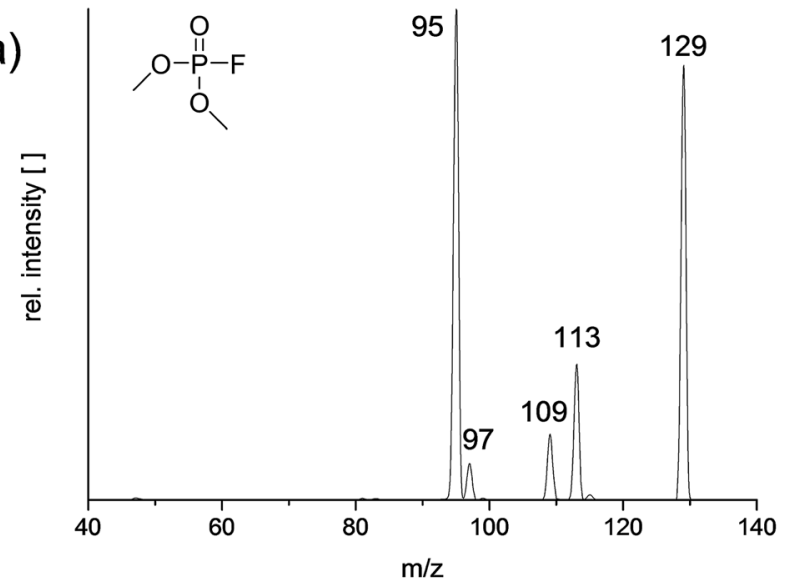

c)

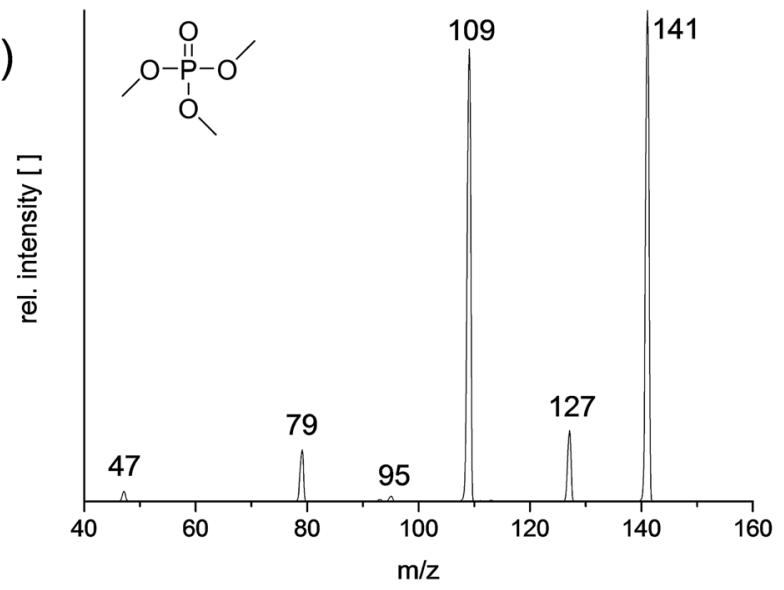

e)

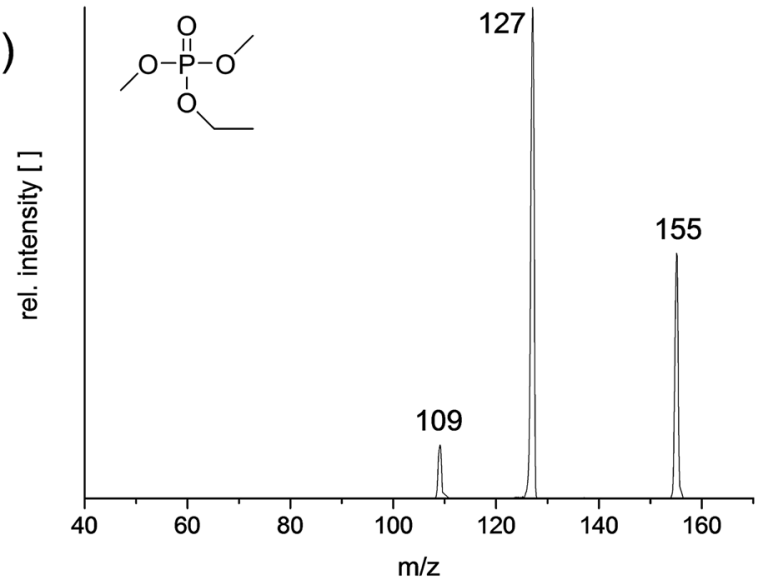

b)

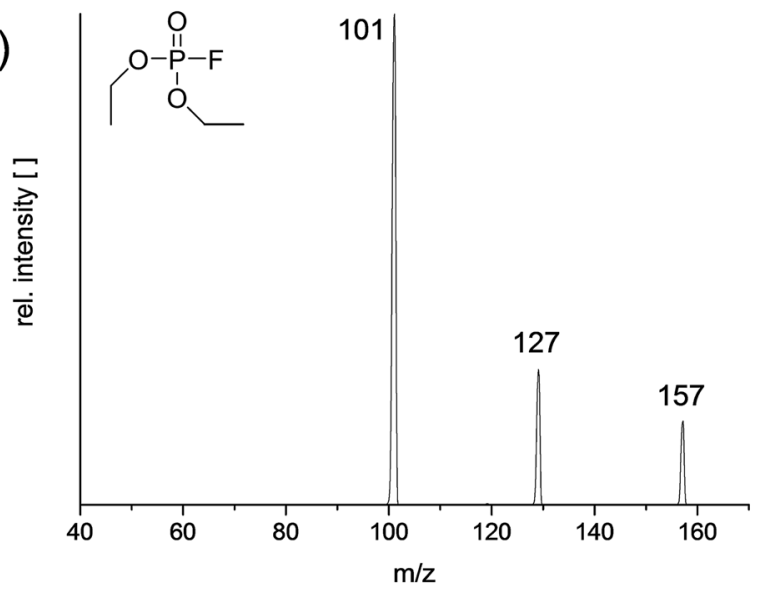

d)

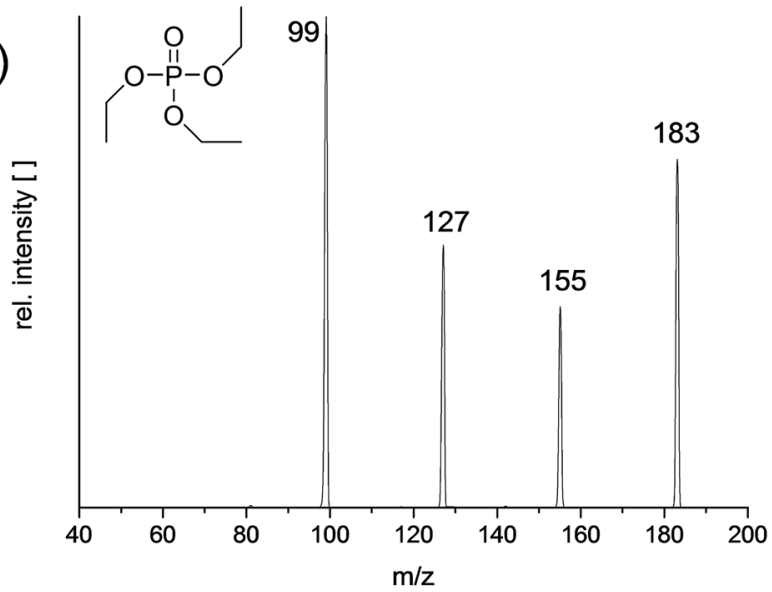

f)

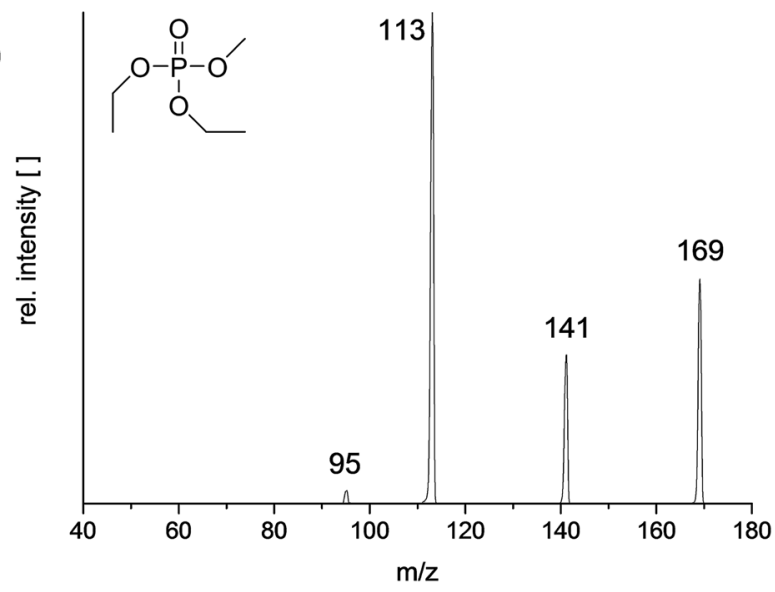

Fig. 2 Fragmentation patterns of DMFP (a), DEFP (b), TMP (c), TEP (d), DMEP (e) and DEMP (f) obtained in a product ion scan mode. 


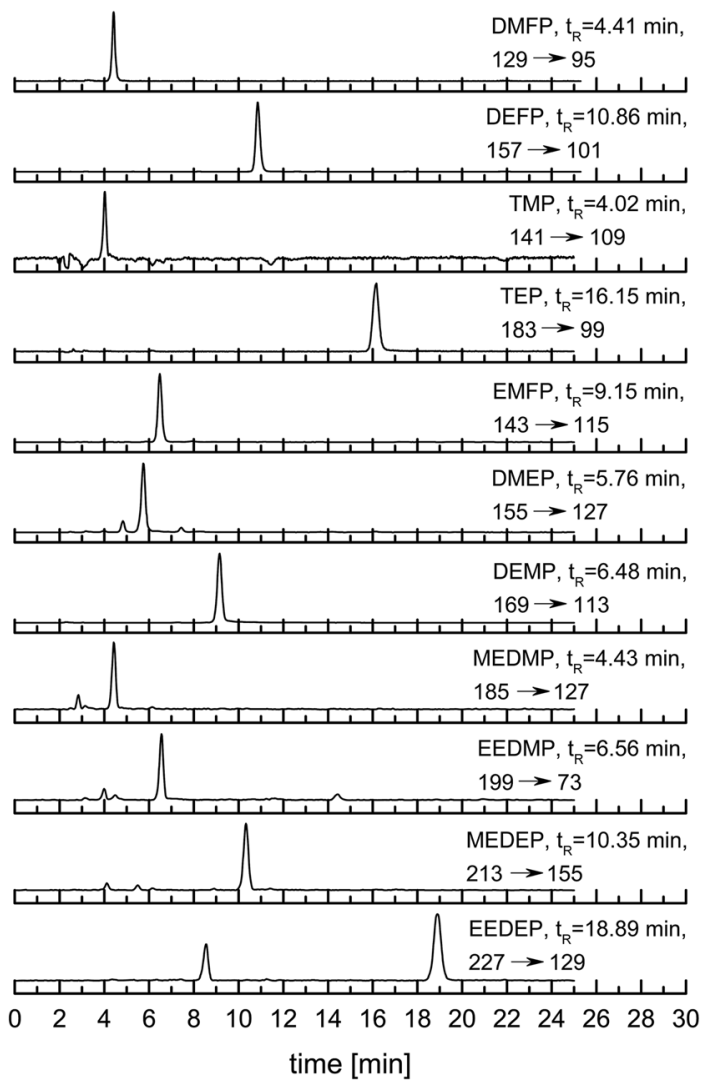

Fig. 3 MRM chromatograms of the investigated OPs generated in an electrochemically decomposed LP50 electrolyte. The $y$-axis (intensity in cps) are not shown.

shown in Table 1. The mass spectra of TMP and TEP investigated by LC-MS/MS are known in literature ${ }^{31-33,35}$ and are in agreement with the presented results. Furthermore, the interpretation of the mass spectra is highly facilitated with fragmentation rules for non-ionic OPs, which were systematized by Weissberg et al. ${ }^{38}$ and Schwarzenberg et al. ${ }^{39} \mathrm{~A}$ neutral loss of ethene $\left(\mathrm{m} / \mathrm{z}^{28}\right)$ was observed by DEFP, TEP, DMEP, DEMP, MEDEP and EEDEP. Furthermore, diethylated or triethylated compounds such as DEFP, TEP and DEMP have a multiple loss of ethene in agreement to the rules. Similar fragmentation was observed by MEDMP and MEDEP or EEDMP and EEDEP with the neutral loss of methyl vinyl ether $(\mathrm{m} / z$ 58) and ethyl vinyl ether $(\mathrm{m} / \mathrm{z} 72)$, respectively. In addition, fragments with $\mathrm{m} / z 59$ or $\mathrm{m} / \mathrm{z} 73$ were detected in mass spectra of these compounds, which indicates protonated methyl vinyl ether or ethyl vinyl ether, respectively. A characteristic cleavage by TMP and DMFP is the loss of $-m / z 32$ as methanol followed by addition of water. The water addition as a possible reaction was discussed in literature. ${ }^{39}$

\subsection{Development of LC-MS/MS methods}

The addition of organic solvents to an aqueous eluent increases the ionization yield because of the decrease of the surface tension and consequently a more effective de-solvation of the analytes. ${ }^{40}$ Fig. 3 shows the MRM chromatograms of the studied OPs in the electrochemically decomposed electrolyte. The chromatographic measurements were performed with $40 \%$ $\mathrm{MeOH}$ on a reversed phase. The addition of $20 \mathrm{mM} \mathrm{HCOOH}$ as a proton donor source for the ionization is necessary in order to suppress the secondary ionization effect with $\mathrm{NH}_{4}{ }^{+}$and $\mathrm{Na}^{+}$, which were present as contaminants in the ESI source. The peak shapes measured with a $40 \% \mathrm{MeOH}$ eluent besides slightly tailed TMP are in general symmetric. The elution sequence of the analytes depends on the number of alkyl groups and their chain length of the analyte and it bases on the hydrophobic interaction with stationary phase of C18 column. According to this finding, among the alkyl fluorophosphates and trialkyl phosphates, the highest retention time is observed with TEP. The ethylene glycol group of MEDMP, EEDMP, MEDEP and EEDEP decreases the adsorption of these analytes on the stationary phase, which results in high distribution degree in the mobile phase leading to shorter retention times. The analysis time with applied parameters is about $25 \mathrm{~min}$, which is also sufficient for the complete elution of all unknown compounds observed in the TIC mode. The applied MRM transitions are specific in regard to the studied OPs (see Fig. 3). In the last chromatogram of EEDEP, an additional peak with the MRM transition $227 \rightarrow 129$ at $8.5 \mathrm{~min}$ is observable. It should be noticed, that a standard for EMFP was not available. Nevertheless, the MRM transition $143 \rightarrow 115$ (loss of ethene) indicates a peak at $t_{\mathrm{R}}=4.41 \mathrm{~min}$. The retention time for this compound is between the values for DMFP $\left(t_{\mathrm{R}}=9.15 \mathrm{~min}\right)$ and DEFP $\left(t_{\mathrm{R}}=\right.$ $10.86 \mathrm{~min})$, which additionally confirms EMFP.

In Fig. 4, a global scheme for the decomposition mechanism of $\mathrm{LiPF}_{6} /$ linear organic carbonates electrolyte with focus on the formation of inorganic and organic phosphates identified in this work is illustrated. The reaction of a cyclic carbonate, EC, with $\mathrm{POF}_{3}$ is similar. ${ }^{10,20}$ Furthermore, the scheme summarizes the so far applied techniques for the separation and detection of the analytes. $\mathrm{POF}_{3}$ is sequently alkylated to produce non-ionic compounds, which are detectable by GC-MS ${ }^{20}$ and/or LC-MS/ MS. Other products of the reaction are $\mathrm{CO}_{2}$ and alkyl fluorides, whose identification by GS-MS was performed by Gachot et $a .^{11}$ The fluorinated phosphates are hydrolyzed in parallel reaction. The separation and identification of hydrolyzed products was performed in our previous works by IC-MS ${ }^{27,30}$ and IC-MS/MS. ${ }^{27,30,41}$ The phosphorus containing compounds $\mathrm{POF}_{3}$ and alkyl difluorophosphate were not investigated in this work. But their formation in degraded electrolytes detected by GC-MS was discussed in literature. ,0,20,27 $^{2}$

\subsection{Quantification of organophosphates}

A typical method for quantifications of analytes by LC-MS/MS is the external calibration using analytical standards. The disadvantage of this method constitutes the dependence on matrix effects leading to suppression or enhancement of the signal intensity of target analytes. The possibility to determine this effect is described by Chen et al..$^{37}$ The investigation of the suppression effects were performed for two independent electrochemically aged cells and two thermal aged electrolytes. The methods applied for the determination of OPs, M1 and M2, were used for quantification experiments. The results obtained 


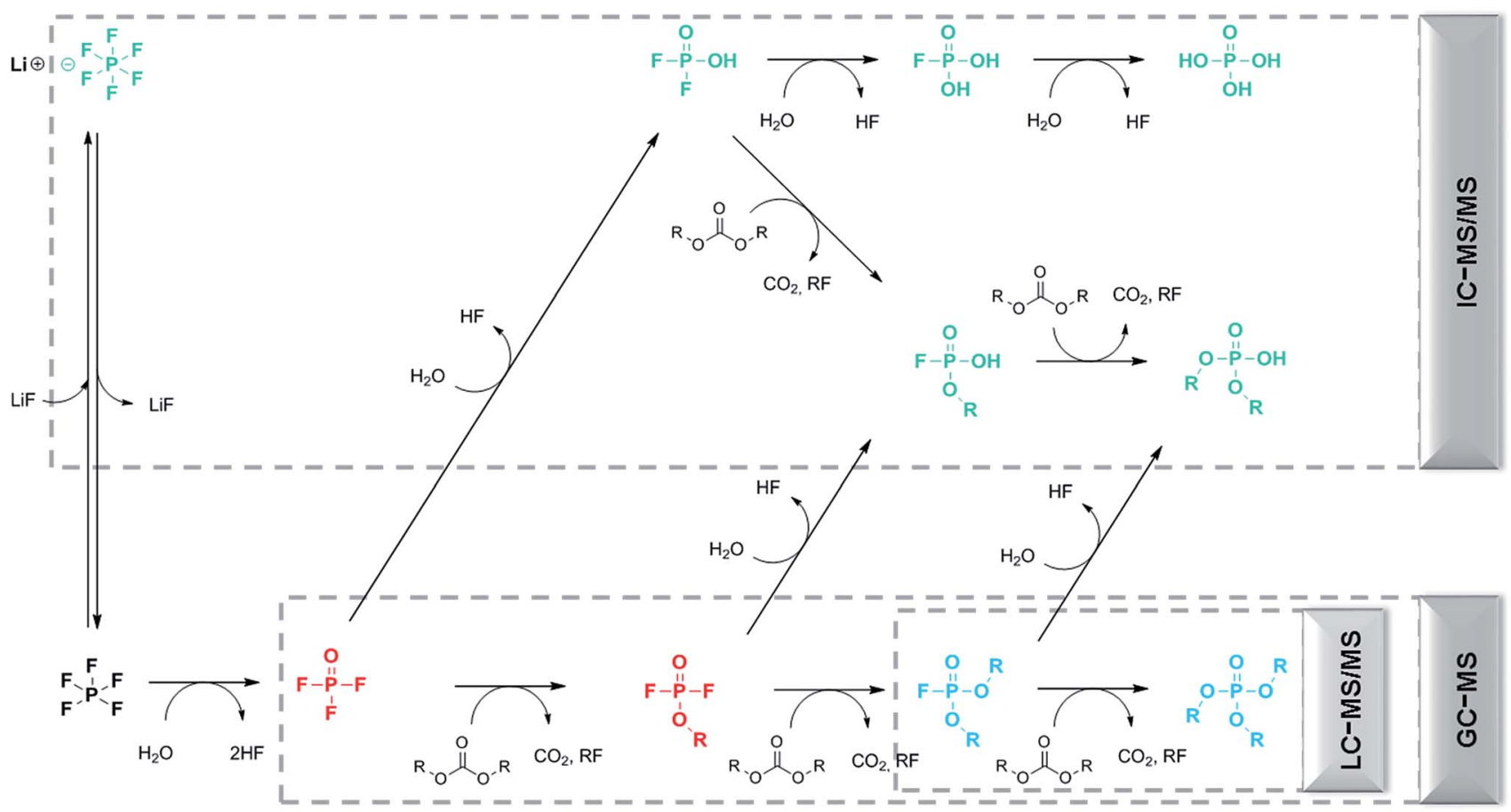

\section{IC: Ion Chromatography LC: Liquid Chromatography GC: Gas Chromatography \\ MS: Mass Spectrometry \\ MS/MS: Tandem Mass Spectrometry}

R: $-\mathrm{CH}_{3}$ or $-\mathrm{CH}_{2} \mathrm{CH}_{3}$

Phosphates identified by IC-MS/MS

Phosphates identified by GC-MS

Phosphates identified by LC-MS/MS and GC-MS

Fig. 4 A global scheme for the thermal or electrochemical decomposition mechanism of LiPF 6 /linear organic carbonate mixture based electrolyte with a focus on the formation of inorganic and organic phosphates resulting from IC-MS/MS, GC-MS and LC-MS/MS analysis.

Table 2 Matrix effects (\%) of the investigated organophosphates ( $E_{i}$ : electrochemically decomposed electrolyte; $T_{i}$ : thermally decomposed electrolyte). The dilution factor for DMFP and DEFP studies is $1: 100$ in ACN. TMP and TEP were investigated by a $1: 300$ dilution. RSD values are showed in brackets

\begin{tabular}{lllll}
\hline Sample & DMFP & DEFP & TMP & TEP \\
\hline $\mathrm{E}_{1}$ & $92.6(21.0)$ & $99.8(2.9)$ & $75.4(5.9)$ & $175.5(8.5)$ \\
$\mathrm{E}_{2}$ & $109.2(5.8)$ & $118.4(7.2)$ & $63.2(5.5)$ & $91.1(0.1)$ \\
$\mathrm{T}_{1}$ & $95.5(4.0)$ & $93.1(9.5)$ & $90.2(6.2)$ & $77.4(4.2)$ \\
$\mathrm{T}_{2}$ & $99.0(1.0)$ & $99.8(6.8)$ & $84.6(8.5)$ & $81.5(10.0)$
\end{tabular}

for DMFP, DEFP, TMP and TEP are collected in Table 2. In the ideal case, the percentage values should be $100 \%$, resulting in no matrix effects. The most results for DMFP and DEFP are close to the ideal values. The differences can be explained by errors of sample preparation and detection, but the errors are in an acceptable range. It can be concluded, that both fluorophosphates are not significantly suppressed by the matrix at the applied dilution of $1: 100$ of the measured samples. The quantification of DMFP and DEFP with the developed LCMS/MS method was carried out (see Table 3). In addition, GC-MS was applied to validate the results of the developed LCMS/MS method. The correlation coefficients $\left(R^{2}\right)$ are $>0.992$ for both analytes and ensure an accurate determination. The results for both dialkyl fluorophosphates measured with LCMS/MS and GC-MS correlate well. The concentration of DMFP and DEFP in both sample types with $0.05-0.2 \mathrm{wt} \%$ is quite high and indicates strong decomposition of the electrolyte.

In contrary to the dialkyl fluorophosphates, the quantification of TMP and TEP is strongly dependent on matrix effects due to their low content in samples, which results in high

Table 3 Concentration of DMFP and DEFP (ppm) in the investigated electrolyte samples measured with LC-MS/MS or GC-MS (E i $_{i}$ electrochemically decomposed electrolyte; $T_{i}$ : thermally decomposed electrolyte). The RSD is stated in brackets

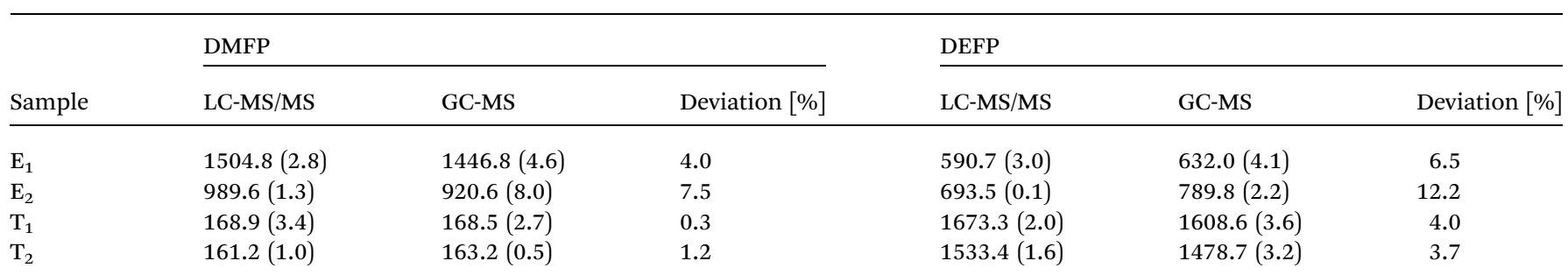


Table 4 Concentration of TMP and TEP [ppm] in the investigated electrolyte samples measured with LC-MS/MS $\left(E_{i}\right.$ : electrochemically decomposed electrolyte; $T_{i}$ : thermally decomposed electrolyte). The RSD is stated in brackets

\begin{tabular}{lll}
\hline Sample & TMP & TEP \\
\hline $\mathrm{E}_{1}$ & $15.9(3.6)$ & $60.3(2.1)$ \\
$\mathrm{E}_{2}$ & $4.0(0.8)$ & $8.7(3.1)$ \\
$\mathrm{T}_{1}$ & $3.5(1.8)$ & $22.4(2.9)$ \\
$\mathrm{T}_{2}$ & $4.0(2.9)$ & $21.3(3.6)$
\end{tabular}

suppression effects. In preliminary tests, a suppression of approximately $50 \%$ accompanied by bad reproducibility was observed for TMP and TEP upon dilution by a factor of 1 to 100 . As it was discussed by Stuber $e t$ al., sample dilution can reduce matrix effects. Nevertheless, the decrease of sensitivity resulting from the dilution is compensated by a low LOD of trialkyl phosphates. ${ }^{42}$ The instrumental LODs for TMP and TEP are much lower compared to GC-MS as it is shown in Table S1. $\dagger$ The dilution factor of 1 to 300 minimizes the suppression from the range of $27-9 \%$ (see Table 2). Furthermore, an increase of the ionization is observed in $\mathrm{E}_{1}$ sample for TEP. Despite the observed suppression effects, the concentration for trialkyl phosphates could be determined. It is up to two magnitudes lower compared to DMFP and DEFP and indicates a low decomposition degree of dialkyl fluorophosphates in the studied electrolytes in according to the proposed degradation mechanism (see Fig. 4) (Table 4).

\section{Conclusions}

This paper reports the first reversed phase LC tandem MS method for identification and quantification of organophosphates in an electrochemically and thermally decomposed $\mathrm{LiPF}_{6}$-based lithium ion battery electrolyte. This method relies on the separation of compounds on the reversed phase and the detection of the analytes in a multiple reaction monitoring mode, which avoids the non-specificity of the total ion current and the selective ion monitoring modes. In total, the commercially available or synthesized standards of eleven organophosphates were baseline separated and investigated with a product ion scan. The measurement with determined MRM transitions allow the quantification of the analytes including the study of suppression effects caused by a matrix, which was demonstrated selectively on DMFP, DEFP; TMP and TEP. The content of highly hazardous DMFP and DEFP measured in an at $95{ }^{\circ} \mathrm{C}$ thermally decomposed and at $5.5 \mathrm{~V}$ electrochemically treated electrolytes is very high; it was determined in the range from 0.02 to $0.16 \mathrm{wt} \%$. The concentration of these compounds could be determined by a dilution of $1: 100$, since the suppression effects were negligible at the studied decomposition stage of the electrolytes. Furthermore, the determined concentration could be validated by GC-MS.

The quantification of the much lower concentrated TMP and TEP (up to two orders of magnitude) were performed with a higher dilution degree. The dilution of samples $1: 300$ showed moderate suppression (27-9\%). Hence, the higher dilution minimized the matrix effects, but also decreased the sensitivity. However, this circumstance was compensated by the low limits of detection (140-150 ppb) of the LC-MS/MS method for the studied trialkyl phosphates. Alternatively, a standard addition as a matrix independent quantification method instead of the external calibration could be an alternative. The validation by GC-MS was not performed due to uncertainties during the determination by this technique in contrast to the developed method.

\section{Acknowledgements}

The state of North Rhine-Westphalia is acknowledged for funding the project OptiLIB (n1102ck010a).

\section{References}

1 B. Scrosati and J. Garche, Lithium batteries: Status, prospects and future, J. Power Sources, 2010, 195(9), 24192430.

2 R. Wagner, N. Preschitschek, S. Passerini, J. Leker and M. Winter, Current research trends and prospects among the various materials and designs used in lithium-based batteries, J. Appl. Electrochem., 2013, 43(5), 481-496.

3 V. Etacheri, R. Marom, R. Elazari, G. Salitra and D. Aurbach, Challenges in the development of advanced Li-ion batteries: a review, Energy Environ. Sci., 2011, 4(9), 3243-3262.

4 D. Liu, W. Zhu, J. Trottier, C. Gagnon, F. Barray, A. Guerfi, A. Mauger, H. Groult, C. M. Julien, J. B. Goodenough and K. Zaghi, Spinel materials for high-voltage cathodes in Liion batteries, RSC Adv., 2014, 4(1), 154-167.

$5 \mathrm{M}$. Hu, X. L. Pang and Z. Zhou, Recent progress in highvoltage lithium ion batteries, J. Power Sources, 2013, 237, 229-242.

6 J. H. Kim, N. P. W. Pieczonka and L. Yang, Challenges and Approaches for High-Voltage Spinel Lithium-Ion Batteries, ChemPhysChem, 2014, 15(10), 1940-1954.

$7 \mathrm{~K} . \mathrm{Xu}$, Nonaqueous liquid electrolytes for lithium-based rechargeable batteries, Chem. Rev., 2004, 104(10), 4303-4417.

8 H. Schranzhofer, J. Bugajski, H. J. Santner, C. Korepp, K. C. Moller, J. O. Besenhard, M. Winter and W. Sitte, Electrochemical impedance spectroscopy study of the SEI formation on graphite and metal electrodes, J. Power Sources, 2006, 153(2), 391-395.

9 E. Kramer, T. Schedlbauer, B. Hoffmann, L. Terborg, S. Nowak, H. J. Gores, S. Passerini and M. Winter, Mechanism of Anodic Dissolution of the Aluminum Current Collector in $1 \mathrm{M}$ LiTFSI EC: DEC $3: 7$ in Rechargeable Lithium Batteries, J. Electrochem. Soc., 2013, 160(2), A356-A360.

10 C. L. Campion, W. T. Li and B. L. Lucht, Thermal decomposition of $\mathrm{LiPF}_{6}$-based electrolytes for lithium-ion batteries, J. Electrochem. Soc., 2005, 152(12), A2327-A2334.

11 G. Gachot, P. Ribiere, D. Mathiron, S. Grugeon, M. Armand, J. B. Leriche, S. Pilard and S. Laruelle, Gas Chromatography/ Mass Spectrometry As a Suitable Tool for the Li-Ion Battery 
Electrolyte Degradation Mechanisms Study, Anal. Chem., 2011, 83(2), 478-485.

12 L. Yang, B. Ravdel and B. L. Lucht, Electrolyte Reactions with the Surface of High Voltage $\mathrm{LiNi}_{0.5} \mathrm{Mn}_{1.5} \mathrm{O}_{4}$ Cathodes for Lithium-Ion Batteries, Electrochem. Solid-State Lett., 2010, 13(8), A95-A97.

13 S. D. Silver, The toxicity of dimethyl-, diethyl-, and diisopropyl fluorophosphate vapors, J. Ind. Hyg. Toxicol., 1948, 30(5), 307-311.

14 R. Gotor, A. M. Costero, S. Gil, M. Parra, R. Martinez-Manez and F. Sancenon, A Molecular Probe for the Highly Selective Chromogenic Detection of DFP, a Mimic of Sarin and Soman Nerve Agents, Chem.-Eur. J., 2011, 17(43), 11994-11997.

15 F. M. Raushel, Chemical byology: Catalytic detoxification, Nature, 2011, 469(7330), 310-311.

16 M. Grutzke, S. Kruger, V. Kraft, B. Vortmann, S. Rothermel, M. Winter and S. Nowak, Investigation of the Storage Behavior of Shredded Lithium-Ion Batteries from Electric Vehicles for Recycling Purposes, ChemSusChem, 2015, 8(20), 3433-3438.

17 C. L. Campion, W. T. Li, W. B. Euler, B. L. Lucht, B. Ravdel, J. F. DiCarlo, R. Gitzendanner and K. M. Abraham, Suppression of toxic compounds produced in the decomposition of lithium-ion battery electrolytes, Electrochem. Solid-State Lett., 2004, 7(7), A194-A197.

18 L. Terborg, S. Weber, S. Passerini, M. Winter, U. Karst and S. Nowak, Development of gas chromatographic methods for the analyses of organic carbonate-based electrolytes, $J$. Power Sources, 2014, 245, 836-840.

19 G. Gachot, S. Grugeon, I. Jimenez-Gordon, G. G. Eshetu, S. Boyanov, A. Lecocq, G. Marlair, S. Pilard and S. Laruelle, Gas chromatography/Fourier transform infrared/mass spectrometry coupling: a tool for Li-ion battery safety field investigation, Anal. Methods, 2014, 6(15), 6120-6124.

20 W. Weber, V. Kraft, M. Grutzke, R. Wagner, M. Winter and S. Nowak, Identification of alkylated phosphates by gas chromatography-mass spectrometric investigations with different ionization principles of a thermally aged commercial lithium ion battery electrolyte, J. Chromatogr. A, 2015, 1394, 128-136.

21 M. Grutzke, V. Kraft, W. Weber, C. Wendt, A. Friesen, S. Klamor, M. Winter and S. Nowak, Supercritical carbon dioxide extraction of lithium-ion battery electrolytes, $J$. Supercrit. Fluids, 2014, 94, 216-222.

22 M. Grutzke, X. Monnighoff, F. Horsthemke, V. Kraft, M. Winter and S. Nowak, Extraction of lithium-ion battery electrolytes with liquid and supercritical carbon dioxide and additional solvents, RSC Adv., 2015, 5(54), 43209-43217.

23 G. Gachot, S. Grugeon, M. Armand, S. Pilard, P. Guenot, J. M. Tarascon and S. Laruelle, Deciphering the multi-step degradation mechanisms of carbonate-based electrolyte in Li batteries, J. Power Sources, 2008, 178(1), 409-421.

24 L. Gireaud, S. Grugeon, S. Pilard, P. Guenot, J. M. Tarascon and S. Laruelle, Mass spectrometry investigations on electrolyte degradation products for the development of nanocomposite electrodes in lithium ion batteries, Anal. Chem., 2006, 78(11), 3688-3698.
25 S. Laruelle, S. Pilard, P. Guenot, S. Grugeon and J. M. Tarascon, Identification of Li-based electrolyte degradation products through DEI and ESI high-resolution mass spectrometry, J. Electrochem. Soc., 2004, 151(8), A1202-A1209.

26 B. Vortmann, S. Nowak and C. Engelhard, Rapid Characterization of Lithium Ion Battery Electrolytes and Thermal Aging Products by Low-Temperature Plasma Ambient Ionization High-Resolution Mass Spectrometry, Anal. Chem., 2013, 85(6), 3433-3438.

27 M. Grützke, V. Kraft, B. Hoffmann, S. Klamor, J. Diekmann, A. Kwade, M. Winter and S. Nowak, Aging investigations of a lithium-ion battery electrolyte from a field-tested hybrid electric vehicle, J. Power Sources, 2015, 273, 83-88.

28 V. Kraft, M. Grutzke, W. Weber, M. Winter and S. Nowak, Ion chromatography electrospray ionization mass spectrometry method development and investigation of lithium hexafluorophosphate-based organic electrolytes and their thermal decomposition products, J. Chromatogr. A, 2014, 1354, 92-100.

29 V. Kraft, M. Grutzke, W. Weber, J. Menzel, S. WiemersMeyer, M. Winter and S. Nowak, Two-dimensional ion chromatography for the separation of ionic organophosphates generated in thermally decomposed lithium hexafluorophosphate-based lithium ion battery electrolytes, J. Chromatogr. A, 2015, 1409, 201-209.

30 L. Terborg, S. Weber, F. Blaske, S. Passerini, M. Winter, U. Karst and S. Nowak, Investigation of thermal aging and hydrolysis mechanisms in commercial lithium ion battery electrolyte, J. Power Sources, 2013, 242, 832-837.

31 A. Bacaloni, C. Cavaliere, P. Foglia, M. Nazzari, R. Samperi and A. Lagana, Liquid chromatography/tandem mass spectrometry determination of organophosphorus flame retardants and plasticizers in drinking and surface waters, Rapid Commun. Mass Spectrom., 2007, 21(7), 1123-1130.

32 E. Martinez-Carballo, C. Gonzalez-Barreiro, A. Sitka, S. Scharf and O. Gans, Determination of selected organophosphate esters in the aquatic environment of Austria, Sci. Total Environ., 2007, 388(1-3), 290-299.

33 X. W. Wang, J. F. Liu and Y. G. Yin, Development of an ultrahigh-performance liquid chromatography-tandem mass spectrometry method for high throughput determination of organophosphorus flame retardants in environmental water, J. Chromatogr. A, 2011, 1218(38), 6705-6711.

34 R. Rodil, J. B. Quintana and T. Reemtsma, Liquid chromatography-tandem mass spectrometry determination of nonionic organophosphorus flame retardants and plasticizers in wastewater samples, Anal. Chem., 2005, 77(10), 3083-3089.

35 J. Tollback, D. Tamburro, C. Crescenzi and H. Carlsson, Air sampling with Empore solid phase extraction membranes and online single-channel desorption/liquid chromatography/mass spectrometry analysis: Determination of volatile and semi-volatile organophosphate esters, J. Chromatogr. A, 2006, 1129(1), 1-8. 36 J. Kasnatscheew, R. W. Schmitz, R. Wagner, M. Winter and R. Schmitz, Fluoroethylene Carbonate as an Additive for 
gamma-Butyrolactone Based Electrolytes, J. Electrochem. Soc., 2013, 160(9), A1369-A1374.

37 D. Chen, R. J. Letcher and S. G. Chu, Determination of nonhalogenated, chlorinated and brominated organophosphate flame retardants in herring gull eggs based on liquid chromatography-tandem quadrupole mass spectrometry, $J$. Chromatogr. A, 2012, 1220, 169-174.

38 A. Weissberg and S. Dagan, Interpretation of ESI(+)-MS-MS spectra-Towards the identification of "unknowns", Int. J. Mass Spectrom., 2011, 299(2-3), 158-168.

39 A. Schwarzenberg, F. Ichou, R. B. Cole, X. MachuronMandard, C. Junot, D. Lesage and J. C. Tabet, Identification tree based on fragmentation rules for structure elucidation of organophosphorus esters by electrospray mass spectrometry, J. Mass Spectrom., 2013, 48(5), 576-586.

40 N. B. Cech and C. G. Enke, Practical implications of some recent studies in electrospray ionization fundamentals, Mass Spectrom. Rev., 2001, 20(6), 362-387.

41 V. Kraft, M. Grützke, W. Weber, M. Winter and S. Nowak, Ion chromatography electrospray ionization mass spectrometry method development and investigation of lithium hexafluorophosphate-based organic electrolytes and their thermal decomposition products, J. Chromatogr. A, 2014, 1354, 92-100.

42 M. Stuber and T. Reemtsma, Evaluation of three calibration methods to compensate matrix effects in environmental analysis with LC-ESI-MS, Anal. Bioanal. Chem., 2004, 378(4), 910-916. 